\title{
„EMOTIONAL INTELLIGENCE AND COMMUNICATION IN HUMAN RESOURCES MANAGEMENT TO AVOID OCCUPATIONAL STRESS"
}

\author{
DAMBEAN Camelia Angelica \\ Departament Engineering and Management \\ University of Medicine, Pharmacy, \\ Sciences and Technology "George Emil Palade"of Târgu Mureș \\ Gh. Marinescu, Târgu Mureș, 5400139, Mureș, Romania \\ dambean.camelia-angelica.20@stud.umfst.ro
}

\begin{abstract}
This study is part of a larger paper and brings to the fore a topical issue in today's society, namely the importance of emotional intelligence in interpersonal relationships in an organization, its connection with the ability of individuals to communicate empathetically, directly, concisely in properly manage working time to avoid occupational stress. This article includes: basics about the importance of emotional intelligence in an organization, the causes of organizational stress, and factors that lead to decreased job satisfaction. The article includes the objective, purpose, research hypothesis, conceptual basis and methodology, tools for measuring stress, emotional intelligence and professional communication.
\end{abstract}

Key words: emotional intelligence, stress, communication, time management

\section{Introduction}

Nowadays emotional intelligence can be an essential element of the connection between feelings, character and moral instincts. There are many people who give in to impulses, not having control over them. The ability to control impulses is the basis of will and character, and the root of altruism is found in empathy. Each emotion gives us the impulse to act in a distinct direction, each indicates the right direction in resolving the conflict situations generated by stressors.

According to some researchers, emotions are generally affective reactions of medium intensity and which have a relatively short intensity and which is often accompanied by changes in the organic sphere. Emotion is a defense system and sometimes it can affect the individual's ability to react and speed up.

Emotion is an emotional, automatic, intense and short-lived state that appears in relation to a certain

(C) 2021 Published by University Press. This is an open access article under the CC BY-NC-ND license (http://creativecommons.org/licenses/CC-BY-4.0/) situation. Emotion can be a mental state induced by one or more internal or external stimuli [1] [2] [3] [4] that cause chemical bodily changes.

Every emotion has a triggering event that can be internal or external, but this emotion is often accompanied by a thought, or an interpretation of the event.

And the term emotional intelligence was first coined in the U.S. by Wayne Leon Payne in 1985, who considers that emotional intelligence involves a creative relationship with states of fear, pain and desire (cf. Roco, 2001) [5].

Emotions affect organizations at all levels and in all spheres, including their external relationships. (Ostell 1996, 552) [6].

E.L. Thorndike has identified emotional intelligence since 1920 by defining it as social intelligence, ie an ability to know how to behave wisely in human relationships. Communication is very
en access article under the CC BY-NC-ND license 
important in the managerial process because it means perception, interpretation, evaluation and selection. If the participants in the communication are numerous and the level of preparation, mentality, habits and personalities are varied but they reach the objectives, and the obstacles that appear in the communication can be numerous.

Emotional intelligence has an important role for motivation in work, motivation that leads to success. The person with emotional intelligence understands the deep meaning of his aspirations and the selfmotivation skills needed to achieve his goals and objectives.

Mayer and Salovey $(1990,1993)$ [7] consider that emotional intelligence involves:

- the ability to perceive emotions as correctly as possible and to express them;

- the ability to access or generate feelings when they facilitate thinking;

- the ability to know and understand emotions and to regulate them in order to promote emotional and intellectual development.

Emotions often influence the motivation for an activity and information processing activities, information that can be distorted by emotions depending on the mood of the person.

Researcher Dr. Karl Albrecht in his book Stress and the Manager, defined 4 types of stress that can be caused by: time; situation; interaction and anticipation. The stress caused by storms caused due to deadlines, there is a rush in activity which leads to unsatisfactory effects. Stress caused by a certain anticipatory situation creates a state of insecurity and agitation accompanied by negative thinking. Stress caused by the situation occurs when certain opportunities arise, circumstances that appear unexpectedly taking by surprise the person who does not know how to react, such as an accident at work, a malfunction of a machine, a minor mistake due to lack of capacity of self-control of the individual acquires a major connotation, situations of interpersonal conflict.

The stress caused by the interaction is often found in anxious, introverted people, dominated by emotions when they have to support their point of view in front of other interlocutors or dominant people, managers.[11]

Contemporary opinion has focused on motivating, by emotions, adaptive behaviors in the ancestral environment [8].

Our own feelings can prevent communication with a certain person. When the person feels a certain strong emotion, instead of responding immediately, it is advisable to identify his emotion so as not to impede the message. Most of the time when a critical message is received, the response is aggressive, but a person with increased emotional intelligence examines their reactions to various situations and exercises a positive response to realize how emotional response can influence the way they communicate. verbal or nonverbal with the interlocutor.[9]
The style of organizational communication takes over the individual elements of the organization and the characteristics of organizational communication are generated by the economic identity, the totality of the values of each form. The collection of data regarding the characteristics of the respective branch is strictly necessary in the process of individualizing the communication system. The communication style consists of a set of manifestation features specific to a person in the communication process.

The present study was conducted to respond to organizational needs to improve the organizational climate that may have consequences on the professional performance of employees and the ability or style of interpersonal communication.

In any human community, communication is the main piece for the proper functioning of the activity. In order to have a correct communication, there must be a continuous exchange of messages that have a purpose that educates to a finality. A correct exchange of messages can activate the motivation and emotion of the interlocutor.

If the manager communicates empathetically and directly, having a clear message then the organizational communication is at the expected, expected level.

Communication is a main process through which there is an exchange of messages and information to achieve the planned purpose and objectives, this being the fundamental element underlying the coordination function, facilitating the approach of managers to synchronize and harmonize the actions of employees of the organization. The messages and information communicated are interpreted and processed by each employee of the organization, who seeks to evaluate and select important data, in order to reduce uncertainty regarding the understanding, knowledge and execution of the mission and objectives promoted by the organization. Most communication problems occur when there is a difference between the content of the message or the impact that the manager intends to convey to employees and collaborators and the way other members of the organization receive the message. (M. Pereteacu, 2019) [10]

\section{Materials and methods}

The present study was conducted to meet organizational needs of improving the professional environment with an effect on the professional performance at work of employees and the ability to communicate positively, creatively and assertively.

The purpose of the paper is to develop communication skills, to manage stress and time, compliance with rules.

Dependent and independent variables Independent variable:

- Sex, The environment of origin, Age, Total age

Seniority at work, studies

Dependent variables: 
- stress, emotional intelligence, questionnaire for assessing communication skills

The group of subjects consists of 50 female and male subjects, working for a company in Tg. Mures, randomly selected.

The company in Tg. Mures. is a Romanian company based on production as its main activity, being established in 1994, and in 1997 a sister company was established but it is not focused on production, but on product distribution, gasoline, service.

Inside the machine building company, to implement the concept of production quality in production processes.

\section{Data analysis and interpretation}

The parameters included in the research are: sex, age, origin of origin, total seniority seniority in the institution.

The tools used were an interpersonal communication questionnaire, emotional intelligence test and stress test applied to a car construction company in Tg. Mures.

The application periods of the questionnaires were 1.11.2020-1.03.2021, these being part of a set of batteries that will form the basis of a more extensive research.

The random sampling method was used, with the indication to include a larger number of respondent employees. Respondents are in the 20-70 age group

The independent variables (VI) of our study are the following: sex, age, origin of origin

The information obtained, the answers to the interview and the test results were statistically processed through the SPSS program, the results being presented in the form of tables and graphical representations through histograms and diagrams being translated into words.

Independent variables: variable -sex

This independent sex variable has the 2 levels:

- mens

- womens

The whole experimental group was dichotomized and the distribution is as follows:

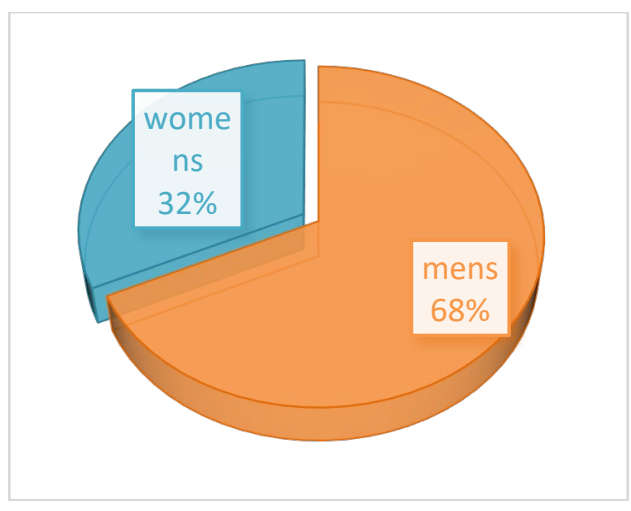

Fig. 1 - Distribution of the subjects from the experimental group highlighted in the study according to sex

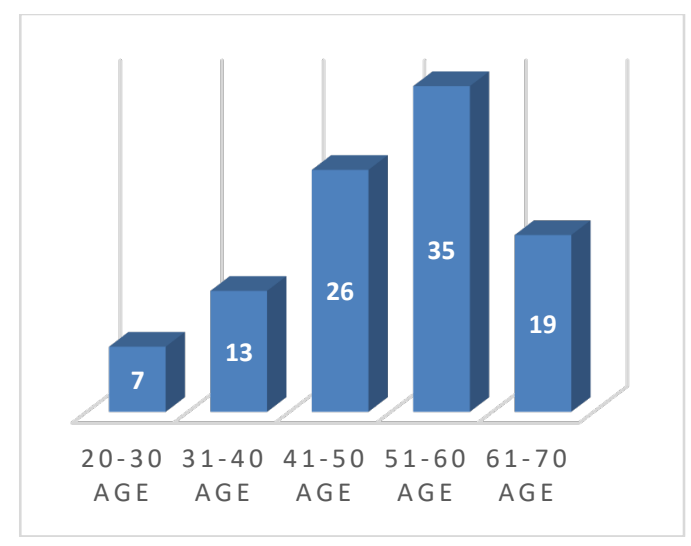

Fig. 2: Distribution by age groups of the subjects studied

From the above histogram it can be seen that the dominant age group is between 40-70 years representing $80 \%$, and the lowest value in terms of age is 27 years, and the highest is 70 years.

The amplitude being 43 years, and the flattening is $(+0,662)$ the positive value indicating a higher peak distribution than the normal distribution.

The asymmetry is $(-0.388)$, the negative value indicating a tail of the frequency distribution in the area of values lower than the average value.

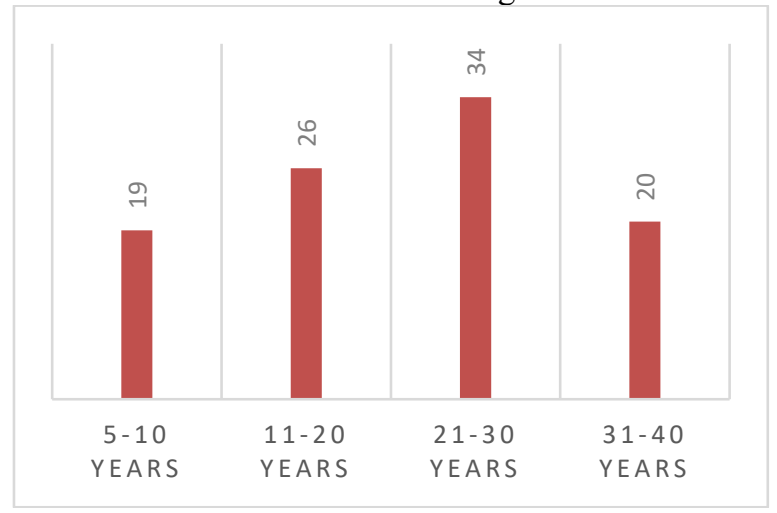

Fig. 3: Distribution by seniority in the institution

From the graph above we can see that the subjects with the highest percentage of $80 \%$ are $11-30$ years old in the institution, which means that those people have a vast experience in order not to create rejections and to collaborate properly. with colleagues and managers. 


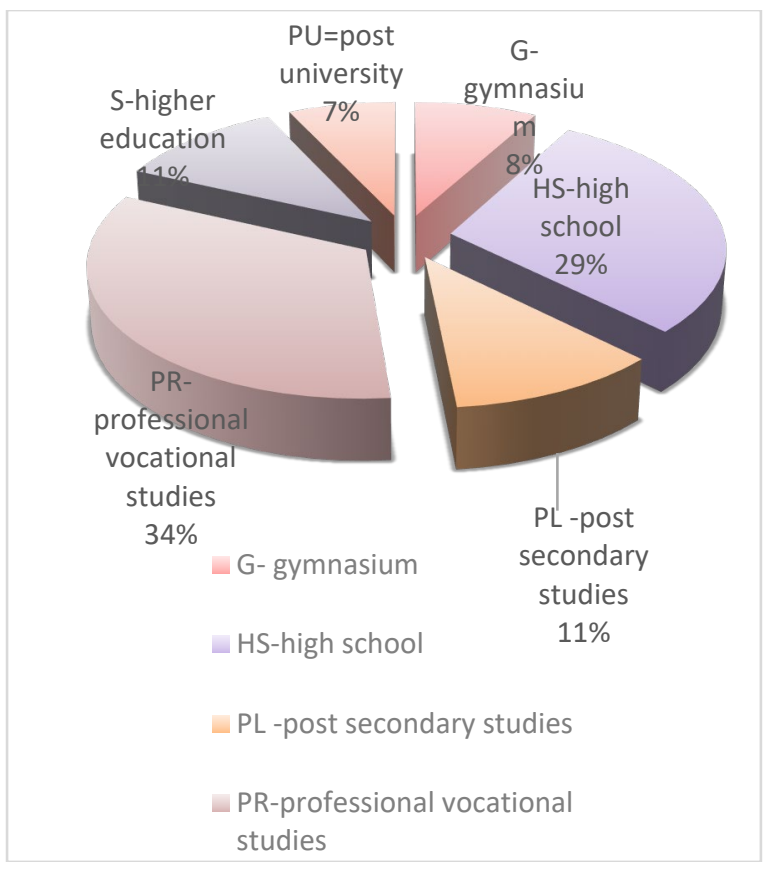

Fig. 4: Distribution of the subjects from the studied group according to studies

The legend G- Gymnasium studies, High school studies, PL-post-secondary studies, PR-professional studies, S-higher education

From the above data we can observe that the dominant group is of people with secondary education representing $82 \%$ being made up of professionals with vocational, secondary, high school and post-secondary education, the workforce being composed of skilled workers with an average age of 20 years, with a vast experience.

Dependent variables Stress test consisting of 25 items, emotional intelligence test consisting of 25 items and the third addictive variable which is the Questionnaire for assessing communication skills consisting of 40 items

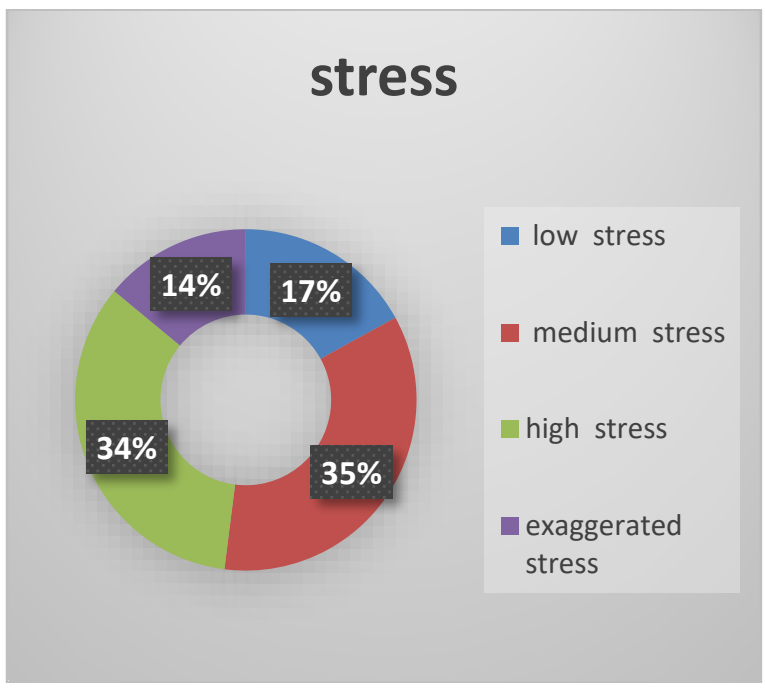

Fig. 5: Distribution of subjects studied in the stress test
As can be seen from our data, employees have a low average stress representing 52\%, which dominates the exaggerated, its share being $14 \%$. Given the current economic situation, it is understandable why the stress level is quite high.

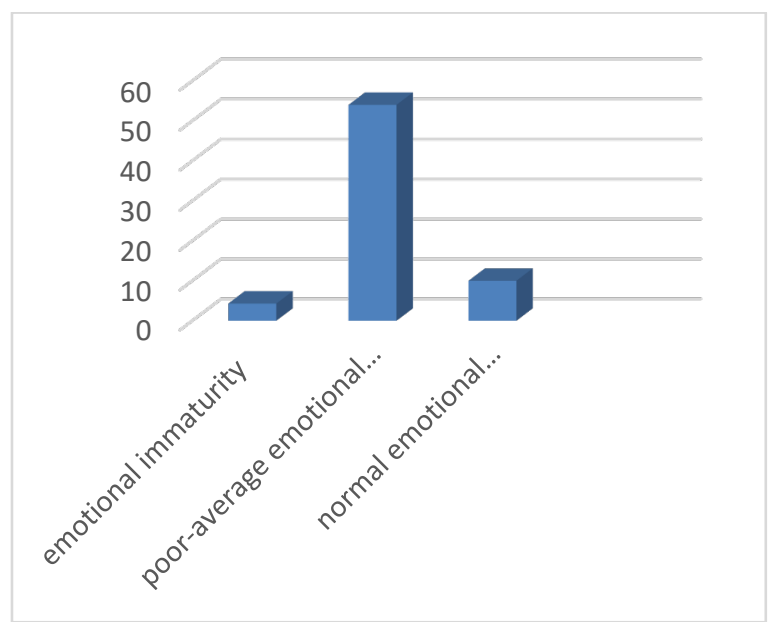

Fig. 6: Distribution of subjects studied in the emotional intelligence questionnaire

From the above distribution we can see that the average employee has a normal average emotional maturity which is $64 \%$.

From the graph above we can see that most employees communicate well with managers and with each other, which leads to the correct execution of activities, because the information transmitted from top to bottom and linear is perceived correctly, $74 \%$ of them being at a level good communication, and $24 \%$ is at an average level of communication.

There is a taxonomy of the work context which is divided into three main categories, namely: interpersonal relationships, physical working conditions and structural characteristics of the workplace. Chronic stress can be divided into three categories: behavioral, psychological and physiological, and organizational communication can be formal or informal [3].

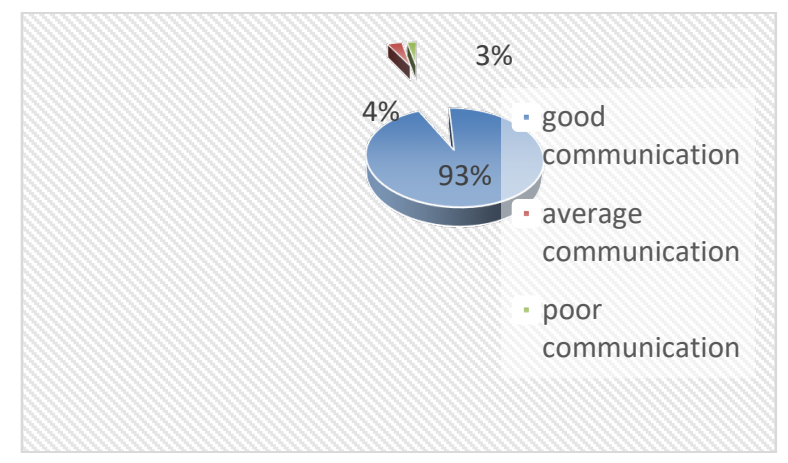

Fig .7: Distribution of subjects studied in the communication test 
Legend: good communication $74 \%$ average communication $24 \%$ poor communication $2 \%$

\section{Results}

A basic assumption underlying this model is that a prerequisite for organizational stress is that there are substantial differences in rewards and costs for those who meet the requirements and those who do not.

Another hypothesis is that there are differences between the information transmitted and the mode of action of employees.

As can be seen, there is a significant close correlation at a significance threshold of $p<0.05$ between:

1. Sex and seniority in the institution-0.289

2. Stress and seniority -0.337

3. Age and stress -0.361

4. Emotional intelligence and stress $-0,294$

From the table above we can see that there is a significant correlation at a significance threshold of $p$ $<0.01$ between:

- Seniority in the institution and total seniority 0.508

- Age and seniority 0.933

\section{Discussion}

We can thus conclude that communication skills are facilitators of emotional intelligence

by modeling contexts and conventions, adopting acceptable behaviors that facilitate a good development of the productive process

emotional intelligence allows the acquisition of intercultural skills that are developed through interpersonal communication, as well as the proper management of emotions that provide a group dynamic.

The organization is a system in which there are organizational problems that can be solved only if there is an efficient communication from top to bottom and from bottom to top, ie from the management team to employers and vice versa. Communication has an important role in the decision-making process.

A communication blockage can lead to stressors which in turn lead to organizational and decision problems. Among the factors that can block effective communication we mention. Communication is a complex process that depends on the structure of success (A. Potang), and the blockages that may occur in the way of communication can be language, cultural barriers, environmental - high noise pollution, perceptual, emotional.

Interpretation From the table above we can see that there is a significant correlation at a significance threshold of $p<0.01$ between:

- Seniority in the institution and total seniority 0.508

- Age and seniority 0.933

\section{Conclusions}

In the current context related to working from home where possible in enterprises, in certain departments and the lack of a clear delimitation between personal and professional life, they have had a negative impact on all those involved in professional activities. they struggled with anxiety, depression and prolonged stress at work, being accompanied by uncertainty and social distancing that have a strong impact on the mental health of $78 \%$ of employees globally causing more stress (38\%), a lack work-life balance (35\%), exhaustion ( $25 \%$ ), depression due to lack of socialization (25\%) and loneliness (14\%).

Following the study conducted by Oracle and Workplace Intelligence on a relatively large number of employees, managers, human resources specialists from 11 countries, showed that the pandemic increased stress, and $42 \%$ of the 12,000 people who represented the sample, said that occupational stress, anxiety, or depression cause their productivity to decline, and $85 \%$ said their personal lives are affected because their professional life is at home or is disrupted by pandemic changes [12].

As can be seen in the present study, employees have an increased level of stress. Factors influencing work involvement are the following: age and seniority.

In general, the involvement increases with age and seniority in the company and this for several reasons:

- on the one hand, as you get older, it becomes difficult to find another job outside the organization. The individual will be inclined to bond more strongly to the present organization;

- on the other hand, involvement is a long process, and older people have had time to strengthen their ties. But the results are not always very sharp and this is because the effect of age and age may intersect with the effect of other factors.

There are frequent situations in which young graduates are heavily involved at the beginning of their careers, given their interest in gaining experience. Involvement will diminish when experience becomes a wealth" on the labor market.

This factor most often leads to a decrease in involvement is the level of training, the higher the level of training of individuals, the less involved they will be. To explain how things really are, we need to consider. Due to the fact that a person with higher education has value and implicitly greater opportunities to find another job in another organization. It is also known that a higher level of training leads to expectations that are increasingly difficult for a company to meet.

Some studies have linked sex to involvement, saying that women are more involved than men. The explanation for this phenomenon starts from the fact that women face more and more and more difficult barriers in their career.

To have an effective response to stress An effective response to stress must use coping strategies 
that develop positive behavioral patterns in such situations [13] to cope with stress people use several behavioral patterns, or coping strategies such as in the state of severe stress [14]. Several studies have examined the methods used by individuals to cope with stress [15], [16], [17].

This often makes them involves more in the life of the organization and give up other activities. Although in this organization the number of women is low due to the specifics of the enterprise, those present give efficiency and are largely satisfied with their work.

According to the data from the statistical processing we can conclude the following:

- The distribution of sex is the same between the categories of stress significance, and the Independent-Samples Test Kruskal-Wallis being 0.487 , which keeps the hypothesis null.

- The distribution of the age variable is the same between the categories of significance of stress, according to the Independent-Samples Kruskal-Walli s calculated Test with values of 0.036 , which rejects the null hypothesis.

The distribution of the variable seniority in the institution is the same between the categories of Significance of stress, according to the IndependentSamples Test Kruskal-Wallisce has a calculated value of 0.008 , which leads to the rejection of the null hypothesis.

The distribution of the EQ score is the same between the strs sign categories. Independent-Samples Kruskal-Wallis Test 0.016 for a significance storm of 0.05 , and the null hypothesis is rejected.

From the statistical data it can be seen that the subjects have a vast professional experience having over $50 \%$ of them 20 years worked in the field of work, most of them having an IQ located at an average level. Emotional intelligence is the ability to understand and manage both one's own emotions and those of others. There have been studies that have shown that the ability to perceive, understand and regulate one's own emotions and those of others is necessary to achieve a better emotional state, ie high levels of emotional intelligence that result in greater well-being (Fernández -Berrocal et al., 2017) [18].

The concept is increasingly used, and some experts believe that people who show emotional intelligence have the ability to adapt their thinking and behavior to the context or to achieve certain goals.

\section{References}

[1] SetThings.com. 25 Dec. 2019.

[2] Panksepp, Jaak (2004). Affective Neuroscience: The Foundations of Human and Animal Emotions. Oxford: Oxford University Press.

[3] Damasio, A. R. (1998). „Emotion in the Perspective of an Integrated Nervous System". Brain Research Reviews. 26 (2-3): 83-86
[4] Ekman, Paul; Davidson, Richard J. (1994). The Nature of Emotion: Fundamental Questions. New York: Oxford University Press.

[5] Cabanac, Michel (2002). „What is emotion?”. Behavioural Processes(60): 69-83

[6] Schacter, Daniel; Gilbert, Daniel; Wegner, Daniel (2010). Psychology. Worth Publishers.

[7] Salovey, P., Mayer, J.D., Goldman, S., Turvey, C., \& Palfai, T. (1993). The Trait Meta-Mood Scale: A measure of mood attention, clarity, and regulation--Three components of emotional intelligence. Unpublished manuscript

[8] Fehr, Beverley; Russell, James A. (1984). "Concept of emotion viewed from a prototype perspective". Journal of Experimental Psychology: General.

[9] Smith, Tiffany (2016). The Book of Human Emotions: From Ambiguphobia to Umpty - 154 Words from Around the World for How We Feel. New York: Little, Brown and Company.

[10] Lewis, Michael; Haviland-Jones, Jeannette M.; Barret, Lisa Feldman (2008). Handbook of emotions. New York: The Guilford Press.

[11] H-Pitariu - Occupational stress in engineers, Psychology magazine no.1 / 1994.

[12] https://blog.ottobroker.ro/care-este-impactulpandemiei-asupra-personalitatii-angajatilor/

[13] Fu, W., Pan, Q., Zhang, C., and Cheng, L. (2020). Influencing factors of Chinese special education teacher turnover intention: understanding the roles of subject well-being, social support, and work engagement, https://doi.org/10.1080/20473869.2020.1780553

[14] Zhao, B., and Huang, Y. X. (2015). Comparative study of occupational well-being of teachers from special education schools and regular schools. J. Mod. Spec. Educ. 5, 56-61.

[15] Mérida-López, S., and Extremera, N. (2017). Emotional intelligence and teacher burnout: a systematic review. Int. J. Educ. Res. 85, 121-130.

[16] Tan, C. C. (2019). Research on the Relationship among Occupational Stress, Emotional Intelligence and Vocational Happiness of Primary and Secondary School Teachers. Master thesis. Changsha: Hu Nan Normal University.

[17] Salovey, P., and Mayer, J. D. (1990). Emotional intelligence. Imag. Cogn. Pers. 9, 185-211.

[18] Fernández-Berrocal, P., Gutiérrez-Cobo, M. J., Rodriguez-Corrales, J., and Cabello, R. (2017). Teachers' affective well-being and teaching experience: the protective role of perceived emotional intelligence. Front. Psychol. 